\title{
Termohigrometria no transporte e na qualidade de ovos destinados ao consumo humano
}

\author{
Rafael C. Silva ${ }^{1}$, José W. B. do Nascimento ${ }^{2}$, Daniele L. de Oliveira ${ }^{2} \&$ Dermeval A. Furtado $^{2}$ \\ ${ }^{1}$ Unidade Acadêmica de Serra Talhada/Universidade Federal Rural de Pernambuco. Serra Talhada, PE. E-mail: rafael_brazil@hotmail.com (Autor \\ correspondente) \\ ${ }^{2}$ Unidade Acadêmica de Engenharia Agrícola/Centro de Tecnologia e Recursos Naturais/Universidade Federal de Campina Grande. Campina Grande, \\ PB. E-mail: wallace@deag.ufcg.edu.br; danielemestre@hotmail.com; dermeval@deag.ufcg.edu.br
}

\section{Palavras-chave:}

avicultura de postura microclima do caminhão unidade Haugh

\begin{abstract}
R E S U M O
A produção de ovos de galinha acompanhando a evolução de pesquisas e o desenvolvimento de projetos inovadores vem ganhando espaço expressivo a cada ano, nos mercados nacional e internacional. Objetivou-se, neste trabalho, avaliar a influência da temperatura do ar e da umidade relativa na qualidade dos ovos de galinha para consumo humano durante o seu transporte entre a granja e o entreposto final. A pesquisa foi conduzida em uma granja de galinhas de postura em Esperança, PB, e foram realizados seis carregamentos. Utilizou-se um caminhão modelo F-4000, sem controle da climatização. Foram utilizados ovos de coloração vermelha de poedeiras semipesadas da linhagem Lohmann (Brown) e avaliados os seguintes parâmetros de qualidade: massa do ovo, gravidade específica, unidade Haugh, espessura de casca, índice de gema e pH. Para a análise estatística foi realizado o teste de Dunnett a 0,05 de probabilidade comparando, assim, as amostras finais com as testemunhas da granja. Foi verificada que, nas condições dos carregamentos, apenas a unidade Haugh apresentou perda de qualidade nas viagens mais longas.
\end{abstract}

\section{Key words:}

laying poultry truck microclimate

Haugh unit

\section{Termohygrometry on the transportation and eggs quality for human consumption}

\begin{abstract}
A B S T R A C T
The production of chicken eggs, following the evolution of research and development of innovative projects, is gaining significance every year in national and international market. The objective of this study was to evaluate the influence of air temperature and relative humidity on the quality of chicken eggs for human consumption during transport between the farm and the final warehouse. The research was conducted on a poultry farm (egg-laying) in Esperança, in the State of Paraíba, Brazil, and six loads were conducted. A F-4000 truck model was used without climate control. Red eggs of Lohmann (Brown) lineage were used and the following quality parameters were evaluated: egg mass, specific gravity, Haugh unit, shell thickness, yolk index and $\mathrm{pH}$. For statistical analysis, the Dunnett's test at 0.05 probability level was performed, thus comparing the final samples with the control from the farm. It was found that under the loading conditions only Haugh unit showed loss of quality during long trips.
\end{abstract}




\section{INTRODUÇÃo}

A avicultura brasileira vem incorporando sistemas automatizados, os quais já são empregados em alguns países grandes produtores de ovos de mesa; desta forma, o Brasil se tem mantido como um dos principais produtores mundiais de ovos.

O ovo é um alimento de alto valor nutricional para o consumo humano; portanto, o produtor deve garantir a qualidade dos ovos que comercializa, por ser este influenciado por alguns fatores, tais como: condições de manejo, instalações, nutrição e o transporte dos ovos, até seu destino final; logo, medidas devem ser tomadas para que os ovos produzidos na granja cheguem ao mercado consumidor limpos, intactos, com aspecto agradável e resguardando a qualidade da produção.

Em geral, os ovos são considerados um alimento saboroso, nutritivo e saudável, porém perecível. $\mathrm{O}$ valor de mercado de um ovo é diretamente determinado pela sua qualidade durante a circulação comercial (Wang et al., 2010). Por se tratar de um alimento perecível, ele pode perder qualidade, desde o momento após a postura, caso não sejam empregadas técnicas adequadas para sua conservação e, mesmo assim, a diminuição de sua qualidade é, de certa forma, inevitável e ocorre de forma contínua a longo do tempo, podendo ainda ser agravado por diversos fatores ambientais e mecânicos (Barbosa et al., 2008).

A qualidade do ovo é determinada por fatores externos e internos. Valor nutricional, sabor, odor, cor da gema, palatabilidade e aparência, são fatores de qualidade que não são facilmente determinados. Do momento em que o ovo é posto até sua comercialização, o principal objetivo é preservar ao máximo sua qualidade original até que ele chegue ao consumidor (Magalhães et al., 2012).

O transporte de ovos dos aviários até o local de seleção e empacotamento deve ser realizado o mais breve possível a fim de reduzir as perdas iniciais da qualidade. Além disto, no caso de transporte dos ovos através de caminhões, medidas devem ser consideradas, tais como: limpeza, desinfecção, climatização de caminhão, além de protegidos contra intempéries. Porém o Brasil, mesmo sendo considerado um país de clima quente, ainda não existe a obrigatoriedade de refrigeração de ovos durante o transporte, sendo os mesmos acondicionados, desde o momento da postura até a distribuição final, em temperaturas ambientes; em alguns casos são refrigerados apenas nas casas dos consumidores (Xavier et al., 2008). Neste contexto, o trabalho teve, como objetivo, avaliar a influência dos parâmetros microclimáticos na carroceria do caminhão na perda de qualidade dos ovos de galinha para consumo humano durante o seu transporte entre a granja e o entreposto final.

\section{Material e Métodos}

O trabalho foi realizado nas regiões do Agreste, Cariri e Seridó do estado da Paraíba; a granja em que foram coletados os ovos, está localizada no município de Esperança. Seis carregamentos que foram realizados para três cidades: Queimadas (Viagem 1), Juazeirinho (Viagem 2) e Serra Branca (Viagem 3) conforme a Tabela 1. Foram realizados três carregamentos durante o mês de abril, considerado "período
Tabela 1. Trajetos, distâncias percorridas e tempo de duração das distribuições de ovos da granja até o entreposto

\begin{tabular}{cccc}
\hline Cidades & $\begin{array}{c}\text { Distância } \\
\mathbf{( k m )}\end{array}$ & $\begin{array}{c}\text { Tempo } \\
\text { de duração (h) }\end{array}$ & Horário \\
\hline Esperança-Queimadas & 43,0 & 1,00 & $8: 15-9: 15$ \\
Esperança-Juazeirinho & 100,0 & 3,50 & $9: 00-12: 30$ \\
Esperança-Serra Branca & 120,0 & 4,00 & $8: 30-12: 30$ \\
\hline
\end{tabular}

seco", e três em setembro, considerados "período chuvoso" de 2013.

Os ovos eram embalados em bandejas com 6 unidades cada uma, em caixas de papel vegetal e embalados com papel filme de PVC, escolhidas de forma aleatória, inclusive as amostras testemunha (bandejas obtidas na própria granja para servir de parâmetro para as demais amostras). As amostras eram conduzidas acondicionadas em caixas térmicas para o Laboratório de Construções Rurais e Ambiência (LaCRA), na Universidade Federal de Campina Grande, PB, após coleta na granja e no entreposto final. Foram utilizados ovos de poedeiras semipesadas da linhagem Lohmann (Brown).

O caminhão de transporte utilizado foi um caminhão modelo F4000 da Ford, com dimensões de 4,35 m de comprimento x 2,18 m de largura x 1,42 m de altura (apenas a carroceria), possuindo carroceria revestida com lona de vinil impermeável, que não apresentava sistema algum de aclimatação interna controlada.

Para obtenção do microclima (temperatura do ar e umidade relativa) da carroceria ao longo da carga de ovos no caminhão, foram instalados 5 sensores tipo HT-500, um em cada bandeja de ovos que eram retirados como amostras para as análises, conforme a Figura 1A (na altura de um metro do piso da carroceria), distribuídos em locais específicos na carroceria do caminhão (Figura 1B).

Para a determinação da massa dos ovos (MO) foi utilizada balança digital com precisão de 0,01 g. O índice de gema (IG) foi calculado através da divisão entre a altura e o diâmetro da gema. Para a determinação da unidade Haugh (UH) foi aferida a altura do albúmen $(\mathrm{mm})$, através do micrômetro analógico utilizado para determinar a altura da gema. Assim, como já havia sido determinada a massa de cada ovo, foi utilizada a Eq. 1, descrita por Pardi (1977), para o cálculo da unidade Haugh:

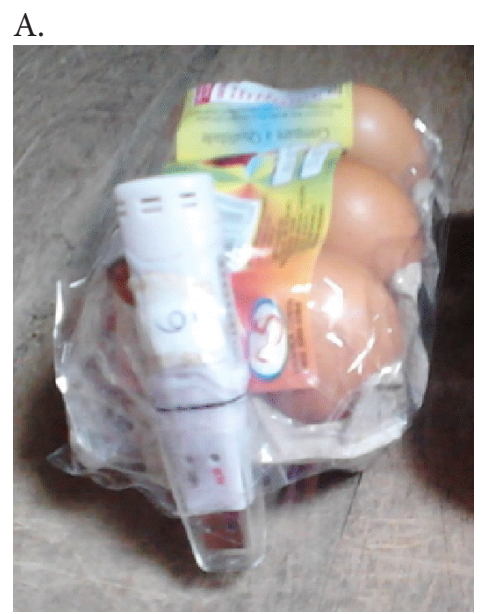

B.

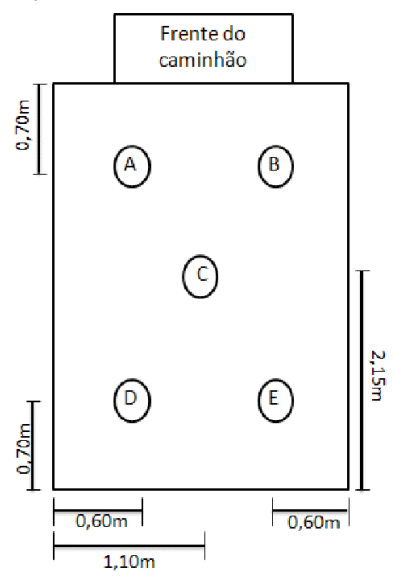

Figura 1. Sensor HT-500 instalado na bandeja de ovos (A) e vista superior da localização dos sensores na carroceria do caminhão (B) 


$$
\mathrm{UH}=100 \log \left(\mathrm{h}+7,57-\mathrm{W}^{0,37}\right)
$$

em que:

$$
\begin{array}{ll}
\text { h } & \text { - altura do albúmen, } \mathrm{mm} \text {; e } \\
\mathrm{W} & \text { - massa do ovo, g. }
\end{array}
$$

A gravidade específica (GE) foi baseada no princípio básico de Arquimedes, em que cada ovo era colocado em um suporte (tipo peneira) e mergulhado em um Becker de 500 $\mathrm{mL}$ contendo água destilada sobre uma balança de precisão de $0,01 \mathrm{~g}$. Durante este processo a temperatura da água foi aferida com termômetro digital tipo espeto, com precisão de \pm $1^{\circ} \mathrm{C}$, sendo este valor utilizado para realizar as correções nos cálculos da gravidade específica. Logo, obtendo-se a massa do ovo imerso na água, a gravidade específica foi determinada usando-se a equação descrita por Hempe et al. (1988) por meio da Eq. 2:

$$
\mathrm{GE}=\frac{\text { massa do ovo no ar }}{\text { massa da água deslocada pelo ovo } \times \text { correção da temperatura }}
$$

A espessura da casca (EC) dos ovos foi realizada sem a remoção das membranas internas da casca e para sua determinação foi utilizado um paquímetro digital. Após os ovos serem quebrados, as cascas foram pesadas ainda úmidas e depois colocadas para secar em estufa a $105^{\circ} \mathrm{C}$ durante $2 \mathrm{~h}$; depois de devidamente secas, as cascas foram pesadas novamente.

Para a determinação do $\mathrm{pH}$ da gema e albúmen, após a quebra dos ovos e das avaliações de altura e diâmetro da gema e albúmen, foi utilizado um medidor de $\mathrm{pH}$ de bancada portátil-MV, modelo mPA- 210/P calibrado previamente com soluções tampão de pH 4,0 e 7,0, para que, separadamente, o $\mathrm{pH}$ da gema e do albúmen fosse medido.

A.

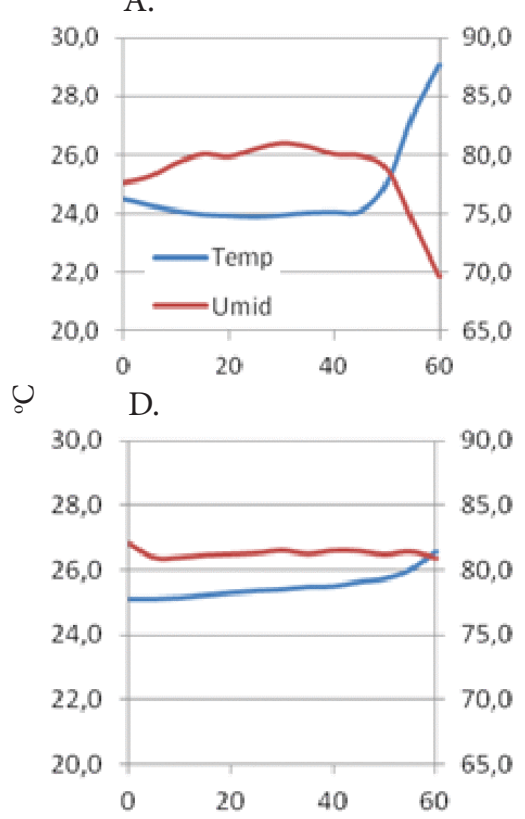

B.
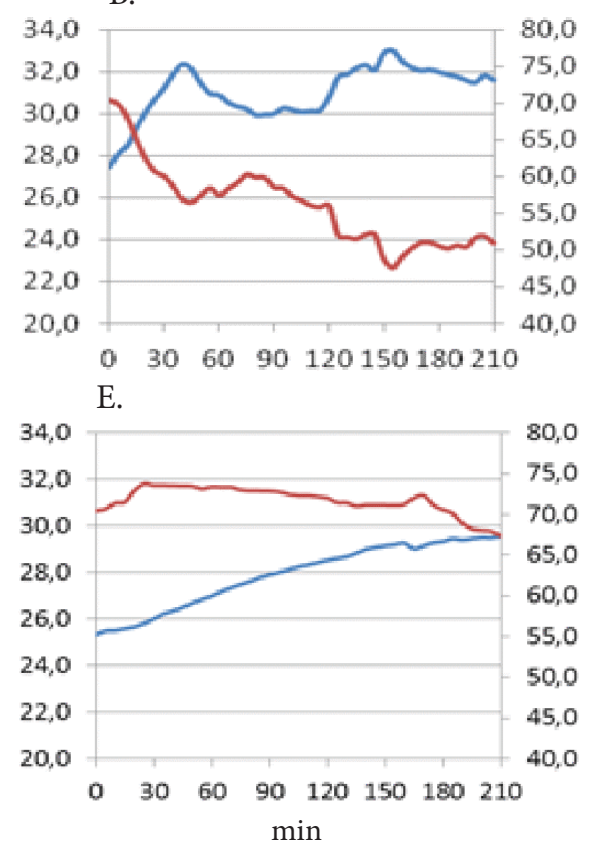

\section{Resultados e Discussão}

As viagens no período seco tiveram maiores amplitudes de temperatura ambiente (TA) e umidade relativa (UR) em relação ao período chuvoso, razão pela qual se deve ter mais atenção no transporte dos ovos no período seco, pois essas variações microclimáticas no transporte podem ser propícias à perda de qualidade e durabilidade dos ovos.

As variáveis TA e UR apresentaram, nas viagens, comportamento específico observando que as viagens no período seco tiveram maiores variações nos valores durante o trajeto da granja ao entreposto final em relação ao período chuvoso (Figuras 2 e 3 ).

Verifica-se, na Figura 2 que nas três viagens realizadas no período seco a amplitude térmica foi maior que nas viagens realizadas no período chuvoso. A exposição do ovo em temperatura e umidade relativa do ar elevadas é, antes do armazenamento, prejudicial à qualidade do ovo, motivo pelo qual é importante o controle das condições do microclima do ambiente após a postura e durante o transporte, a fim de evitar perdas de qualidade dos ovos nessa etapa e favorecer a velocidade dessas perdas nas fases posteriores.

Para os valores da umidade relativa do ar também foram observadas maiores variações no período seco em relação ao chuvoso. A umidade relativa do ar é influenciada por alguns fatores climáticos importantes, como a temperatura, mesmo que não ocorra aumento ou diminuição em seu conteúdo de umidade (Falcão et al., 2010).

Leandro et al. (2005) afirmam que os efeitos do clima tropical, temperatura e umidade relativa do ar, são fatores relevantes que interferem na qualidade dos ovos durante a estocagem.

A refrigeração é significativa na preservação da qualidade interna dos ovos, sendo aconselhável que os ovos saiam da sala de processamento da granja refrigerados em temperatura média de 0 a $4{ }^{\circ} \mathrm{C}$, garantindo, ao consumidor, um produto

Figura 2. Valores da temperatura do ar e umidade relativa na viagem 1 (A), viagem 2 (B) e viagem 3 (C) do período seco; Valores da TA e UR na viagem 1 (C), viagem 2 (D) e viagem 3 (E) do período chuvoso 
A.

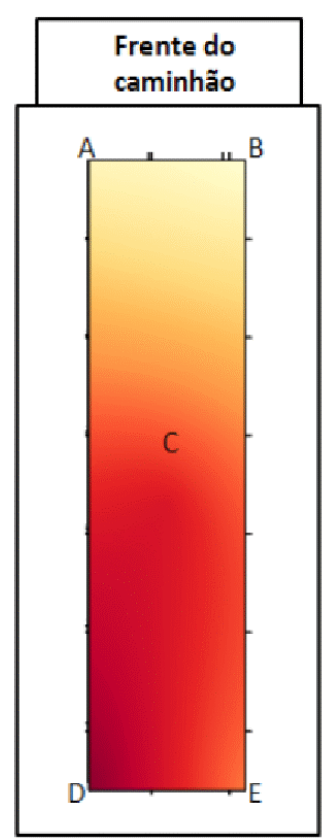

D.

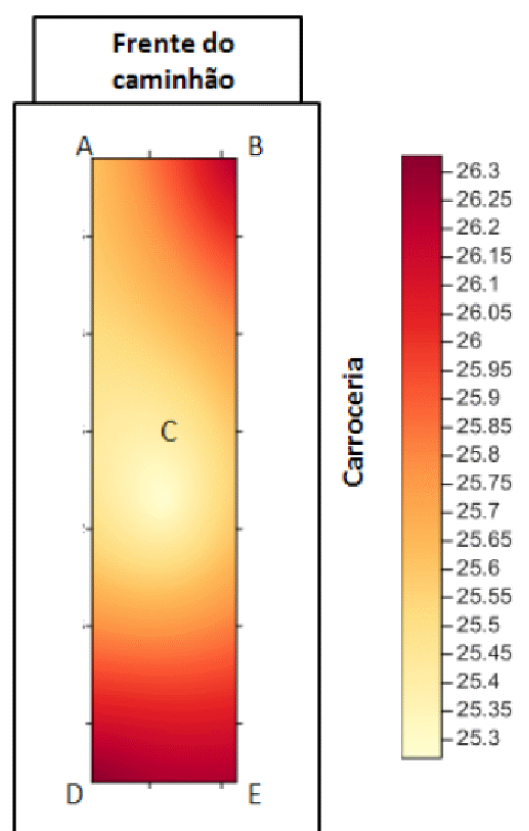

B.

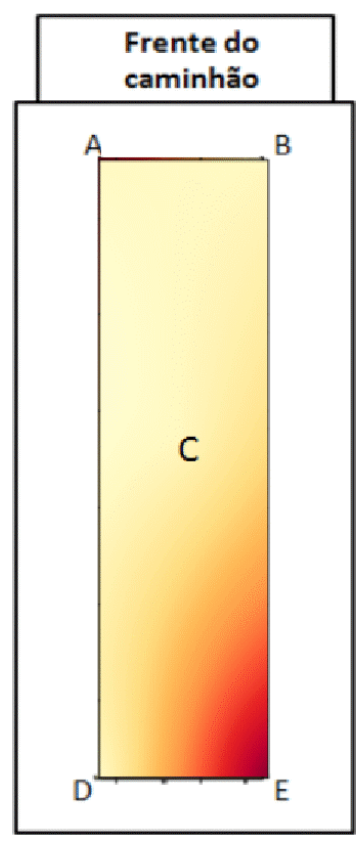

E.

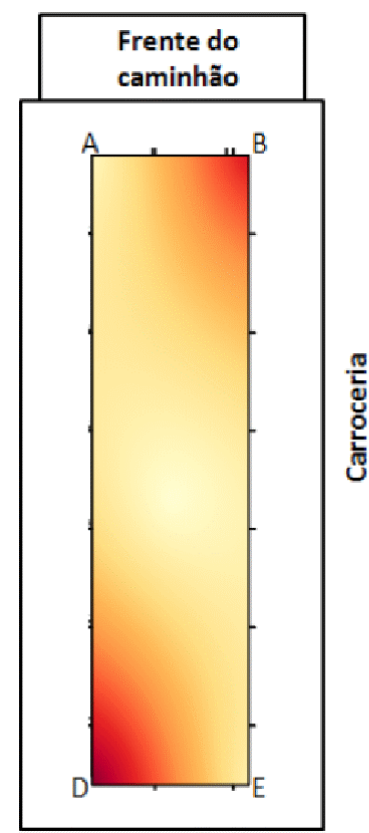

C.
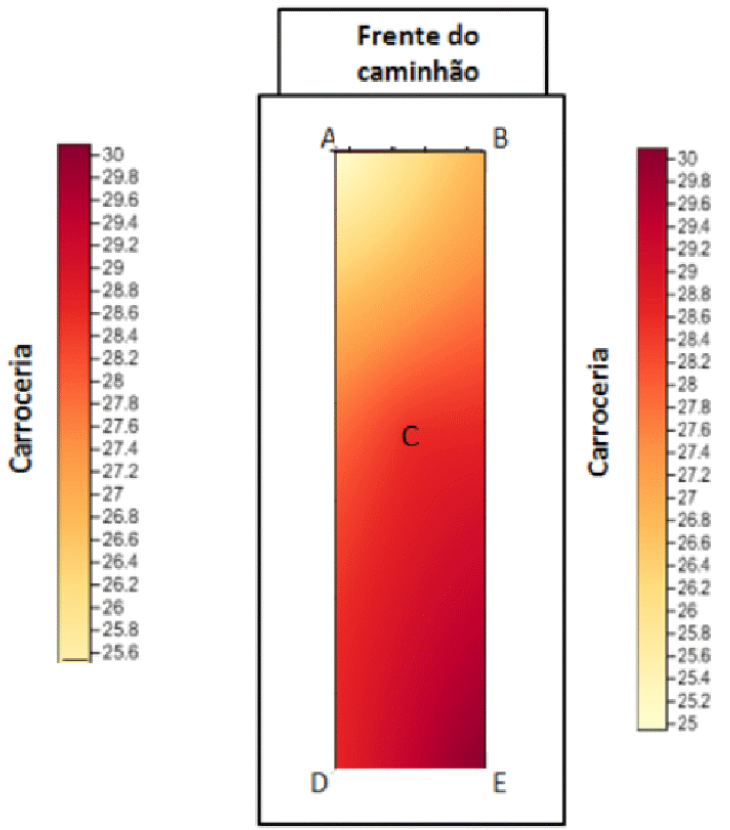

F.

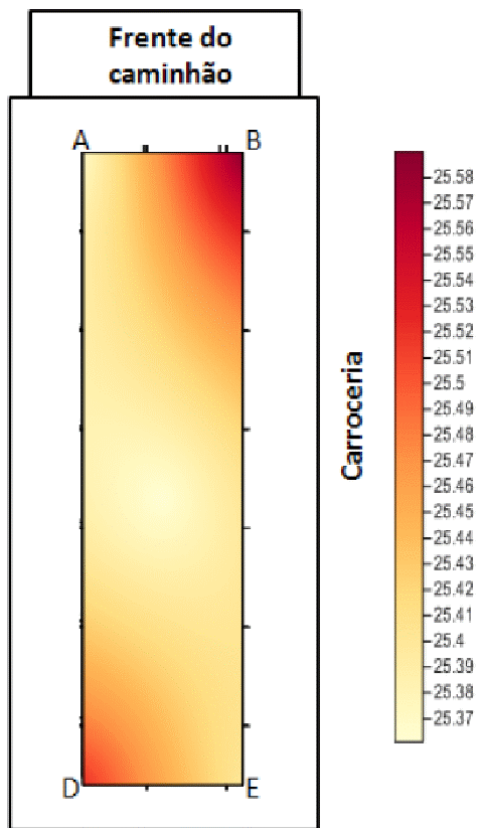

Figura 3. Perfil termográfico médio nas viagens do período seco: viagem 1 (A), viagem 2 (B) e viagem 3 (C) e no período chuvoso: viagem $1(\mathrm{E})$, viagem $2(\mathrm{~F})$ e viagem $3(\mathrm{G})$

saudável, nutritivo, saboroso e com segurança (Carvalho et al., 2003)

Com o aumento da umidade relativa do ar tem-se o início da condensação (também chamada "liquefação", a água em estado de vapor que, ao tocar uma superfície fria, muda para seu estado líquido) sobre os ovos, que resultará em um ambiente mais propício para o crescimento de microrganismos (fungos e bactérias) nos ovos, fato este também observado por Baracho et al. (2010).

Os perfis térmicos da carroceria do caminhão transportador durante o transporte de ovos são apresentados nas Figuras 3, no período seco e no período chuvoso.

Em geral, foi possível observar que na estação seca as temperaturas mais elevadas foram na parte traseira do caminhão, provavelmente pela menor transferência de calor por convecção durante a movimentação do caminhão. No período chuvoso observou-se que as temperaturas mais elevadas ocorreram na região frontal direita e traseira esquerda mostrando que, possivelmente, nesse período a incidência de radiação solar é amena e o efeito da transferência de calor por convecção não foi predominante como no período seco; assim, é provável que os bolsões de temperatura na diagonal sejam devidos à declinação solar no período. As temperaturas médias mais elevadas foram encontradas no período seco; fato semelhante foi observado por Anderson et al. (2008), relatando que as estações do ano exercem forte influência sobre as condições térmicas de caminhões furgão climatizados mas que, no verão, foi considerada a pior época para se transportar ovos haja vista que as regiões próximas ao climatizador e traseira ofereciam piores condições térmicas. Estudos realizados por Patterson et al. (2008) que, analisando o transporte de ovos comerciais, verificaram que no verão os 
ovos ficaram expostos a condições microclimáticas adversas diminuindo, desta forma, sua qualidade e a vida útil, fato também observado neste estudo.

Nazareno et al. (2013) verificaram, analisando o transporte de ovos férteis em caminhões furgão, grande heterogeneidade de temperatura ao longo do perfil do caminhão, cujas maiores temperaturas ocorrem na traseira do caminhão, de forma gradativa, com valores médios de 24,$3 ; 24,9$ e $25,6^{\circ} \mathrm{C}$.

Os valores médios da massa do ovo (MO), gravidade específica (GE), espessura de casca (EC) e índice de gema (IG) não apresentaram diferença significativa nos fatores tempo/ distância de transporte, havendo diferença significativa ( $\mathrm{P}$ $<0,05)$ apenas para a unidade Haugh $(\mathrm{UH})$, visualizados na Tabela 2.

A massa dos ovos (MO) não apresentou diferença significativa entre a testemunha e as amostras finais, nos dois períodos. Os ovos tipo extra analisados (peso mínimo de 60 g unidade ${ }^{-1}$ ), estatisticamente não reduziram seus valores de massa ao longo de seu transporte da granja ao entreposto final, tendo em vista que o transporte dos ovos foi em um tempo máximo de quatro horas (viagem 3). Portanto, em razão do tempo de trajeto relativamente curto, a perda de água neste intervalo foi insignificante. Além disto, as condições higrotérmicas, pelo fato das bandejas estarem embaladas em papel filme de PVC, desfavoreceram a perda de água.

Verifica-se que, em ambos os períodos, nas viagens 2 e 3 , em que houve maior duração nas viagens, ocorreram diferenças significativas no parâmetro de unidade Haugh (Tabela 2) em relação à amostra inicial (testemunha) e como o ovo não perdeu quantidade significativa de água, a diminuição do UH pode ser creditada à perda de dióxido de carbono $\left(\mathrm{CO}_{2}\right)$ durante o transporte.

A redução nos valores da UH está relacionada à queda na qualidade dos ovos, e esta redução está associada principalmente à perda de água e de dióxido de carbono, durante o período de elevação da temperatura do ambiente e por meio da evaporação, tornando a albumina líquida. Perda de gás carbônico resulta em alteração no sabor do ovo, no peso e na altura dos seus componentes diminuindo, assim, sua

Tabela 2. Médias da testemunha e amostras finais dos parâmetros de qualidade dos ovos: massa do ovo (MO), unidade Haugh $(U H)$, gravidade específica $(G E)$, espessura de casca (EC) e índice de gema (IG), comparando as médias finais de cada distância com sua testemunha

\begin{tabular}{lccccc}
\hline $\begin{array}{c}\text { Distância } \\
(\mathbf{k m})\end{array}$ & $\begin{array}{c}\text { MO } \\
\mathbf{( g )}\end{array}$ & $\begin{array}{c}\text { UH } \\
\text { Período seco }\end{array} \begin{array}{c}\text { GE } \\
\left(\mathbf{g ~ m L} \mathbf{~}^{-1}\right)\end{array}$ & $\begin{array}{c}\text { EC } \\
(\mathbf{m m})\end{array}$ & IG \\
Testemunha (0) & 66,98 & 76,35 & 1,035 & 0,38 & 0,44 \\
$1(43,0)$ & 64,68 & 76,13 & 1,041 & 0,39 & 0,41 \\
$2(100,0)$ & 64,95 & $67,22^{*}$ & 1,040 & 0,39 & 0,43 \\
$3(120,0)$ & 65,98 & $65,24^{*}$ & 1,025 & 0,38 & 0,43 \\
C.V.(\%) & 9,13 & 6,19 & 12,89 & 10,19 & 7,16 \\
\hline \multicolumn{5}{c}{ Período chuvoso } \\
Testemunha (0) & 67,66 & 77,06 & 1,083 & 0,40 & 0,42 \\
$1(430,0)$ & 66,56 & 78,71 & 1,073 & 0,40 & 0,41 \\
$2(100,0)$ & 65,72 & $69,46^{*}$ & 1,057 & 0,41 & 0,40 \\
$3(120,0)$ & 65,82 & $70,90^{*}$ & 1,060 & 0,40 & 0,41 \\
C.V.(\%) & 12,70 & 9,81 & 10,15 & 3,18 & 4,71 \\
\hline
\end{tabular}

As médias seguidas por um asterisco diferem significativamente da testemunha, a 0,05 de probabilidade, pelo teste de Dunnett qualidade (Oliveira, 2012). Segundo Figueiredo et al. (2011), esta análise dá uma indicação da duração e das condições de armazenamento dos ovos sendo que, quanto maior o valor da unidade Haugh, melhor a qualidade do ovo.

Peebles \& McDaniel (2004) consideraram, em seu trabalho, o valor da gravidade específica $1,0800 \mathrm{~g} \mathrm{~mL}^{-1}$ como valor limite entre baixa ou alta qualidade da casca dos ovos. Observando a Tabela 2 é possível verificar que este valor limite de gravidade específica não foi atingido em nenhuma vez, em ambos os períodos. Santos et al. (2009) verificaram que o armazenamento dos ovos comerciais durante 21 dias, independente da temperatura, ocasiona um índice de gravidade específica menor, quando comparado aos ovos com 7 e 14 dias de armazenamento.

Os valores de espessura de casca também não diferiram estatisticamente e, os valores médios variaram entre $0,38 \mathrm{e}$ $0,39 \mathrm{~mm}$ para o período seco e entre 0,40 e $0,41 \mathrm{~mm}$ para o período chuvoso (Tabela 2). Provavelmente, o pouco tempo de transporte, juntamente com as condições higrotérmicas do caminhão, não foi determinante para que a espessura da casca dos ovos fosse alterada. Os resultados desta pesquisa corroboram com os encontrados por Marinho (2011) que não observaram variação na espessura de casca em função da temperatura e do tempo de armazenamento.

De acordo com Souza et al. (2007), a medida que melhor representa a qualidade interna dos ovos, além da unidade Haugh, é o índice de gema. Não houve diferenças significativas para o índice de gema quando comparado com as amostras finais e a testemunha, nos dois períodos (Tabela 2), variando entre 0,40 a 0,43. Samli et al. (2005) citam haver efeito significativo para o índice de gema durante períodos prolongados de armazenamento.

Encontraram-se, analisando o $\mathrm{pH}$ dos albumens e das gemas dos ovos, os valores médios e apresentados na Tabela 3 .

Os valores médios de $\mathrm{pH}$ do albúmen e gema dos ovos analisados nos dois períodos (seco e chuvoso) não apresentaram diferença significativa em relação aos períodos e deslocamentos (Tabela 3), com pH do albúmen variando entre 6,80 a 7,00, estando esses valores abaixo da faixa normal para $\mathrm{pH}$ deste componente descrito por Xavier et al. (2008), que propõem que os valores de $\mathrm{pH}$ do albúmen podem variar de 7,5 a 8,5 .

Tabela 3. Valores médios de $\mathrm{pH}$ do albúmen $(\mathrm{pHA})$ e $\mathrm{pH}$ da gema ( $\mathrm{pHG}$ ) dos ovos quando comparados às amostras finais e às testemunhas

\begin{tabular}{ccc}
\hline Distância $(\mathbf{k m})$ & $\begin{array}{c}\text { pHA } \\
\text { Período seco }\end{array}$ & pHG \\
\hline Testemunha & 6,91 & 7,08 \\
$1(43,0)$ & 6,85 & 6,72 \\
$2(100,0)$ & 7,00 & 6,88 \\
3 (120,0) & 6,90 & 6,99 \\
C.V. (\%) & 6,19 \\
\hline \multicolumn{3}{c}{} \\
Testemunha & Período chuvoso \\
\hline 1 (43,0) & 6,90 \\
\hline (100,0) & 7,00 & 7,01 \\
\hline 3 (120,0) & 6,80 & 6,90 \\
C.V. (\%) & 6,90 & 7,00 \\
\hline
\end{tabular}

As médias seguidas por um asterisco diferem significativamente da testemunha, a 0,05 de probabilidade, pelo teste de Dunnett 
Com relação ao $\mathrm{pH}$ da gema, verifica-se que as mesmas estão próximas da faixa dos valores ideais, conforme Ordónez (2005), ao citar que o $\mathrm{pH}$ da gema fresca é de aproximadamente 6,0 , podendo atingir 6,9. Portanto, o tempo de transporte não causou alterações no $\mathrm{pH}$ das gemas dos ovos, que assim se mantiveram livres de dissociações que pudessem vir a comprometer sua composição química.

\section{Conclusões}

1. Nas viagens da estação seca as temperaturas mais elevadas foram observadas na parte traseira do caminhão e no período chuvoso as temperaturas mais elevadas ocorrem na região frontal direita e traseira esquerda da carroceria.

2. Nos parâmetros de qualidade interna dos ovos nos dois períodos avaliados apenas a unidade Haugh apresentou diminuição nas viagens mais longas.

\section{Literatura Citada}

Anderson, K. E.; Patterson, P. H.; Koelkebeck, K.W; Darre, M. J.; Carey, J. B.; Ahn, D. U.; Ernst, R. A.; Kuney, D. R.; Jones, D. R.; Temperature sequence of eggs from oviposition through distribution: transportation. Poultry Science, v.87, p.1195-1201, 2008. http://dx.doi.org/10.3382/ps.2007-00236

Baracho, M. S.; Nääs, I. A.; Gigli, A. C. S. Impacto das variáveis ambientais em incubatório de estágio múltiplo de frangos de corte. Engenharia Agrícola, v.30, p.563-577, 2010. http://dx.doi. org/10.1590/S0100-69162010000400001

Barbosa, N. A. A.; Sakomura, N. K.; Mendonça, M. O.; Freitas, E. R. Fernandes, J. B. K. Qualidade de ovos comerciais provenientes de poedeiras comerciais armazenados sob diferentes tempos e condições de ambientes. ARS Veterinária, v.24, 127-133, 2008.

Carvalho, F. B.; Stringhini, J. H.; Jardim Filho, R. M.; Leandro, N. S. M.; Pádua, J. T.; Deus, H.A.S.B. Influência da conservação e do período de armazenamento sobre a qualidade interna e da casca de ovos comerciais. Revista Brasileira de Ciência Avícola, v.5, Suplemento, p.100, 2003.

Falcão, R. M.; Galvani, E.; Lima, N. G. B.; Cruz, B. R. P. Análise da variação da umidade relativa do ar do Pico da Bandeira, parque nacional Alto Caparaó, Brasil. In: Seminário Latino-Americano de Geografia Física, 2010, Santa Maria/RS. <http://www.uc.pt/fluc/ cegot/VISLAGF/actas/tema3/rita_falcao $>7$ Dez. 2010.

Figueiredo, T. C.; Cançado, S. V.; Viegas, R. P.; Rêgo, I. O. P.; Lara, L. J. C.; Souza, M. R.; Baião, N. C. Qualidade de ovos comerciais submetidos a diferentes condições de armazenamento. Arquivo Brasileiro de Medicina Veterinária e Zootecnia, v.63, p.712-720, 2011. http://dx.doi.org/10.1590/S0102-09352011000300024

Hempe, J. K.; Lauxwn, R. C.; Savage, J. E. Rapid determination of egg weight and specific gravity using a computerized data collection system. Poultry Science, v.67, p.902-907, 1988. http://dx.doi. org/10.3382/ps.0670902

Leandro, N. S. M.; Deus, H. A. B.; Stringhini, J. H.; Café, M. B.; Andrade, M. A.; Carvalho, F. B. Aspectos de qualidade interna e externa de ovos comercializados em diferentes estabelecimentos na região de Goiânia. Ciência Animal Brasileira, v.6, p.71-78, 2005.
Magalhães, A. P. C; Curvello, F. A.; Morenz, M. J.; Calixto, L. F.; Rezende, S. R. F. Qualidade de ovos comerciais de acordo com a integridade da casca, tipo de embalagem e tempo de armazenamento. Revista de Ciência da Vida, v.32, p.51-62, 2012.

Marinho, A. L. Qualidade interna e externa de ovos de codornas (Coturnix japonica) armazenados em diferentes temperaturas e períodos de estocagem. Maceió: Universidade Federal de Alagoas, 2011. 79p. Dissertação Mestrado

Nazareno, A. C.; Silva, I. J. O.; Vieira, F. M. C.; Camargo, J. R.; Medeiros, S. R. R. Caracterização do microclima dos diferentes layouts de caixas no transporte de ovos férteis. Revista Brasileira de Engenharia Agrícola e Ambiental. v.17, p.327-332, 2013. http:// dx.doi.org/10.1590/S1415-43662013000300012

Oliveira, D. L. Desempenho e qualidade de ovos de galinhas poedeiras criadas em gaiolas enriquecidas e ambiente controlado. Campina Grande: Universidade Federal de Campina Grande, 2012. 87p. Dissertação Mestrado

Ordónez, J. A. Ovos e produtos derivados. In: Tecnologia de alimentos. Alimentos de origem animal. Porto Alegre: Artmed, 2005. p.269279.

Pardi, H. S. Influência da comercialização na qualidade dos ovos de consumo. Rio de Janeiro: Universidade Federal Fluminense, 1977. 73p. Dissertação Mestrado

Patterson, P. H.; Koelkebeck, K.W.; Anderson, K. E.; Darre, M. J.; Carey, J. B.; Ahn, D. U; Ernst, R. A.; Kuney, D. R.; Jones, D. $\mathrm{R}$. Temperature sequence of eggs from oviposition through distribution. Poutry Science, v.87, p.1182-1186, 2008. http:// dx.doi.org/10.3382/ps.2007-00242

Peebles, E. D.; McDaniel, C. D. A practical manual for understanding the shell structure of broiler hatching eggs and measurements of their quality. Mississipi: State University, 2004. 16p.

Samli, H. E.; Agma, A.; Senkoylu, N. Effects of storage time and temperature on egg quality in old laying hens. The Journal of Applied Poultry Research. v.14, p.548-553, 2005. http://dx.doi. org/10.1093/japr/14.3.548

Santos, M. S.V; Espíndola, G. B.; Lôbo, R. N. B.; Fuentes, M. F. F; Carvalho, L. E.; Santos, A. B. E. Desempenho e qualidade dos ovos de poedeiras comerciais submetidas às dietas com diferentes óleos vegetais. Revista Brasileira de Saúde e Produção Animal, v.10, p. 654-667, 2009.

Souza, R. C. S.; Coimbra, J. S. R.; Rojas, E. E. G.; Minim, L. A.; Oliveira, F. C.; Minim, V. P. R. Effect of $\mathrm{pH}$ and salt concentration on the solubility and density of egg yolk and plasma egg yolk. Food and Science Technology, v.40, p.1253-1258, 2007. http://dx.doi. org/10.1016/j.lwt.2006.08.001

Xavier, I. M. C.; Cançado, S. V.; Figueiredo, T. C.; Lara, L. J. C.; Lana, A. M. Q.; Souza, M. R.; Baião, N. C. Qualidade de ovos submetidos a diferentes condições de armazenamento. Arquivo Brasileiro de Medicina Veterinária e Zootecnia, v.60, p.953-959, 2008. http:// dx.doi.org/10.1590/S0102-09352008000400026

Wang, Y.; Wang, J.; Zhou, B.; Lu, Q. Monitoring storage time and quality attribute of egg based on electronic nose. Journal Analytica Chimica Acta, v.650, p.183-188, 2010. 